$40(1) \mid 2011$

Varia

Bogotá, 4-6 de mayo de 2011

«Memoria amazónica en los países andinos:

Antropología e Historia»

Bogotá, 4-6 de mayo de 2011

Jean-Pierre Chaumeil

(e) OpenEdition

Journals

Edición electrónica

URL: http://journals.openedition.org/bifea/1702

DOI: 10.4000/bifea.1702

ISSN: 2076-5827

Editor

Institut Français d'Études Andines

Edición impresa

Fecha de publicación: 1 abril 2011

Paginación: 231-233

ISSN: 0303-7495

Referencia electrónica

Jean-Pierre Chaumeil, « «Memoria amazónica en los países andinos: Antropología e Historia» »,

Bulletin de l'Institut français d'études andines [En línea], 40 (1) | 2011, Publicado el 01 octubre 2011, consultado el 07 noviembre 2020. URL : http://journals.openedition.org/bifea/1702 ; DOI : https:// doi.org/10.4000/bifea.1702

Les contenus du Bulletin de l'Institut français d'études andines sont mis à disposition selon les termes de la licence Creative Commons Attribution - Pas d'Utilisation Commerciale - Pas de Modification 4.0 International. 
Évènements

\section{«MEMORIA AMAZÓNICA EN LOS PAÍSES ANDINOS: ANTROPOLOGÍA E HISTORIA»}

Bogotá, 4-6 de mayo de 2011

Este congreso fue organizado conjuntamente por el IFEA y el Departamento de Antropología de la Universidad Nacional de Colombia, con el respaldo de la Cooperación Regional Francesa para los Países Andinos, la Embajada de Francia en Colombia, el Centro EREA del Laboratoire d'Ethnologie et de Sociologie Comparative (UMR 7186, CNRS-Université Paris Ouest Nanterre-La Défense), la 


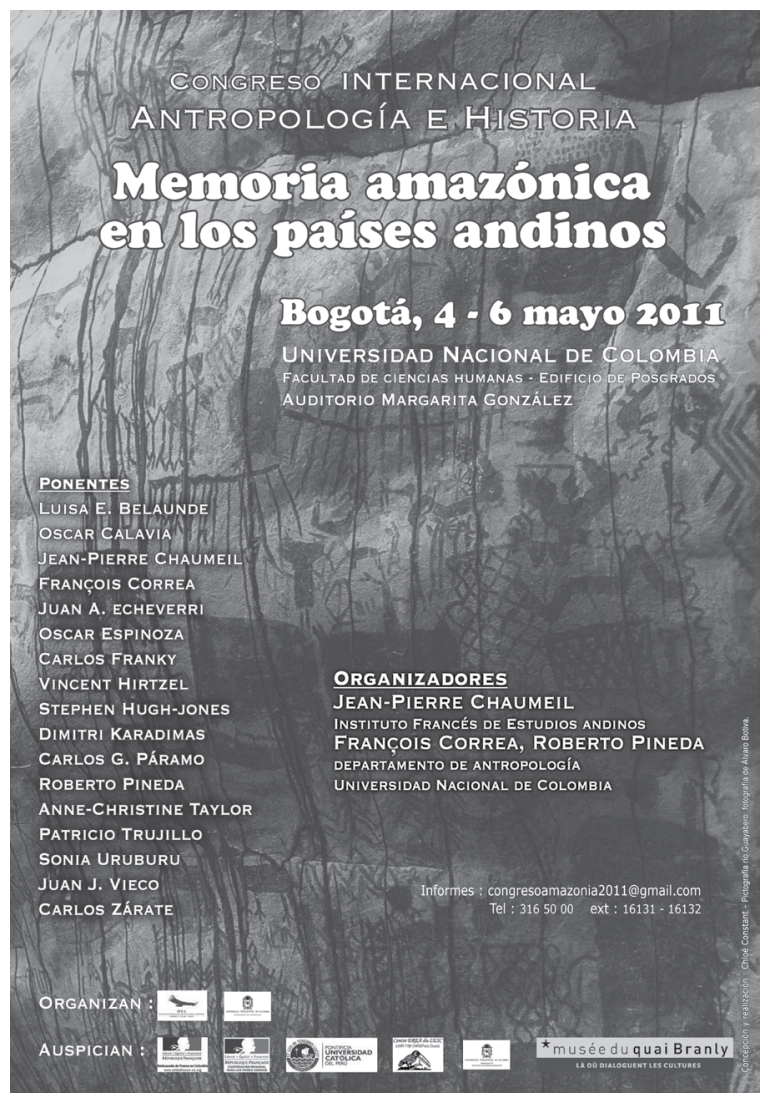

Pontificia Universidad Católica del Perú, el Museo du quai Branly y la Facultad de Ciencias Humanas y Sede de la Amazonía de la Universidad Nacional de Colombia. Dicho acontecimiento tuvo lugar entre el 4 y el 6 de mayo de 2011 en el Edificio de Posgrados (Auditorio Margarita González) de la Facultad de Ciencias Humanas de la Universidad Nacional de Colombia, Bogotá. Fue coordinado por JeanPierre Chaumeil (IFEA), François Correa y Roberto Pineda (UNC) y convocó a investigadores de Colombia (Juan E. Echeverri, Carlos Franky, Carlos Páramo, Sonia Uruburu, Juan J. Vieco, Carlos Zárate), Ecuador (Paricio Trujillo), Bolivia (Vincent Hirtzel), Perú (Luisa E. Belaunde, Oscar Espinosa), Brasil (Oscar Calavia), Francia (Dimitri Karadimas, Anne-Christine Taylor) e Inglaterra (Stephen Hugh-Jones).

Este evento era la continuación de un primer encuentro consagrado a la antropología y la arqueología amazónicas en los países andinos (Lima, noviembre de 2009). Tenía como propósito ampliar la reflexión sobre la antropología de las tierras bajas amazónicas a través de otro tema de mucha importancia para la disciplina, a saber las interconexiones entre Antropología e Historia. Los trabajos realizados últimamente en este campo han cambiado la visión que hasta hace poco se tenía sobre la limitada complejidad de las sociedades nativas de la Amazonía y, al mismo tiempo, han abierto nuevos campos de investigación sobre las formas de historicidad y de la memoria en dichas culturas.

Las intervenciones se organizaron en torno a tres temas centrales. El primero abarcó la cuestión de la historicidad del mito así como la transformación de la historia en mito. El segundo tema confrontó procesos de fabricación de la historia y de su contenido: por ejemplo cuando la historia local se hace oficial, o vice versa. Por fin, el tercer tema permitió reflexionar sobre los procesos de subjetivación y producción de historia personal, y la biografía indígena.

La conferencia inaugural del congreso (Nuestra historia está escrita en las piedras. Modalidades de historia, mitología y escritura en la Amazonia del Noroeste) estuvo a cargo de Stephen Hugh-Jones, profesor del King's College de Cambridge. Esta charla retomó el debate sobre la naturaleza de la escritura y su relevancia con 
respecto a distinciones entre mitología e historia. Suscitó una discusión sobre la necesidad de relacionar los relatos y cantos rituales — considerados como dos modalidades distintas de «mito»- con el paisaje, los petroglifos y las técnicas de la memoria. Dicha conferencia sirvió de introducción general para las otras ponencias que trataron, cada una a su manera y desde distintos puntos de vista, de la relación a la historia, a las identidades y a la memoria, en particular cuando se trata de memoria de genocidio o de violencia política, como en el caso de los witoto y de los asháninka, o también a través de la biografía de ciertos personajes eminentes de la Amazonía. Referente a la producción de géneros autobiográficos, el congreso se cerró precisamente con una comunicación de Anne-Christine Taylor, directora del departamento de investigación y docencia del Museo du quai Branly, sobre el papel de ciertos tipos de rituales lingüísticos en la construcción de la transmisión de la memoria social en los grupos de cultura jivaro. Dicha ponencia fue seguida por un acto final a cargo de S. Hugh-Jones, A.-C. Taylor y J.-P. Chaumeil proponiendo algunas reflexiones sobre el desarrollo de la antropología amazónica y la producción cada vez mayor de escritos (artículos, libros, colecciones, pinturas) por autores indígenas y su relación con formas más tradicionales de mitología e historia, temas que son de mucha actualidad en la Amazonía contemporánea.

El evento dio lugar a un programa de radio de 1 hora de debate en directo «Historia de la Amazonia en los países andinos» en el Programa UN ANÁLISIS de la Universidad Nacional, difundido el día 3 de mayo, con la participación de $\mathrm{S}$. Hugh-Jones, J.-P. Chaumeil, R. Pineda, F. Correa y O. Espinosa. 